\title{
PRODUCTION AND BIOACTIVE SCREENING OF NANO- PARTICLES PRODUCED FROM PLANT EXTARCTS
}

\author{
Nair Sreecha Chandran*, C. Prabha Kumari, \\ KS. Arya Prasad and Reshma RK. Pillai \\ Department of Biotechnology, CEPCI Laboratory and Research \\ Institute, Kollam, Kerala, Thiruvananthapuram, India.
}

\begin{abstract}
Nano-particles are those substances which have a minutesute size mostly ranging in $\mathrm{nm}$ scale. Due to this their surface are by volume ratio is high. And because of this property they are widely used in industries like food, clothes, biomedical, optical, electronic fields etc. Nano-particles are uniform throughout their properties and they are conducting too. They have the amazing property of linking bulk substances with smallest atomic or molecular structures. So many researches are going on these nano-particles to make it much more effective and to use it up to it's fullest.. In the present study $\mathrm{ZnO}$ nano-particles were synthesized from leaves extracts of Lilium candidum and Ocimum tenuiflorum. Further production of nanoparticles from plant extracts was performed. The bacterial and fungal activities were tested and it was found out that nanoparticle enhanced the prohibition of growth of bacteria- Salmonella typhi, Pseudomonas aeruginosa, Listeria monocytogenous, Escherichia coli. and it also prevented the growth of fungiAspergillusniger,Aspergillusflavus, Aspergillusfumigatus, Penicilliumchrysogenum, Rhizopusoryzae. The results evaluated that, In case of bacteria, Lilum candidum (LT) nanoparticles seem to be more effective and for fungi, Ocimum tenuiflorum (TT) was observed to be more effective.
\end{abstract}

Keywords: Nano-particles, ZnO, plant extract, Lilum candidum and Ocimum tenuiflorum.

\section{INTRODUCTION}

Nanoparticles are those substances which has a size lower than $100 \mathrm{~nm}$ at least in 1 dimension. (Batista et al. 2015). Nanoparticles are uniform through out their properties and they are conducting too. At some cases they have special optical properties. (Hewakuruupu Y. L. et al. 2013). Due to their property of having high value of surface area by volume they can be widely used in so many industries, like biomedical, optical, electronic fields etc for applications like fluorescent biological labels, $\mathrm{d}$ rug and gene delivery, bio detection of pathogen, detection of proteins, probing of DNA structure, tissue engineering, tumour destruction via heating, separation and purification of biological molecules and cells, MRI contrast enhancement, phagokinetic studies. Also nano-particles are used in the production of food products, cosmetics, medicine, clothing, disinfectants, households, stain-resistant materials, fuel catalysts etc. The nano-particles can be synthesized in so many techniques including chemical as well as using natural raw materials. Like always, the green synthesis of a substance will be highly advanced because of its ore favoured properties. Lilium candidum aka Madonna lily, is a species cominutesg under the true lily family. It is now at the verge of extinction and recorded by IUCN in the list of near threatened species. (Chadbum $\mathrm{H}$ 2014). It is a native to Middle East as well as Asia. is used in medical field against carcinogenic factors, ulcers, tumors, external inflammations etc and it is also used in the production of tincture and ointments. And the pollen grain of Lilium candidum is used in the treatment against epilepsy. Ocimum tenuiflorum aka basil, is a perennial plant cominutesg under the family Lamiaceae. It is a native through out Indain sub-continent. (Staples et al. 1999) (Warrier P 
K 1995)It covers a wide range of uses, and mostly in medical field and in anti-infectious preparations. Phytochemical constituents responsible for the medicinal properties are mainly rosmarinic acid ,oleanolic acid, betacaryophyllene, ursolic acid, carvacrol, eugenol, and amounts of linalool and.(Sundaram $R$ et al. 2012). The genome of Ocimum has beem reported with having 612 megabases. (Upadhayy et al. 2015). So, production of nano-particles from these two plants will be useful such that both have antimicrobial as well as antifungal properties. And also threatened species like Lilum candidum could get more attention and protection when it is use commercially.

\section{MATERIALS AND METHODS}

\subsection{Collection of samples}

Leaves of Lilum are collected from Mavelikara, near Kayamkulam of Alleppey district in Kerala. And the leaves of Ocimum are collected from Ramapuram, nr.KayamkulamofAlleppey district in Kerala. First these leaves were rinsed, dried and powdered. And $20 \mathrm{~g}$ of the powdered leaves are weighed and taken in a conical flask and then mixed with $300 \mathrm{ml}$ water which was sterilized once and then the mixtures are again undergone sterilization at $70 \mathrm{n}$ C. After 45 minutes, the solution appeared to be colored with plant extract. And then the solutions containing powdered leaves are filtered using whatman filter paper.

\subsection{Preparation of Nano-particles}

$100 \mathrm{ml}$ of each solutions were taken and were individually and were separately mixed with $100 \mathrm{ml}$ of solution containing $50 \mathrm{ml} 0.1 \mathrm{M}$ Zinc Sulphate and $50 \mathrm{ml} 0.4 \mathrm{M}$ Sodium Hydroxide. And those were put in a shaker for 24 hours, and after 24 hours, pellets were appeared. Then these two solutions were heated on a rectangular hot plate for $1 \mathrm{hr}$ and then cooled and centrifuged for 5 minutes at $5000 \mathrm{rpm}$. Then more pellets are appeared to be present and these were extracted out and put in a china dish and put in a hot air oven for 24 hours to dry.

\subsection{Preparation of broths}

2.3.1 Nutrient broth for bacterial medium.

$0.5 \mathrm{~g}$ of peptone along with $0.3 \mathrm{~g}$ beef extract and $0.5 \mathrm{~g} \mathrm{NaCl}$ were mixed with $100 \mathrm{ml}$ of distilled water and was undergone sterilization for 45 minutes. And then this broth was equally divided in 5 test tubes.

2.3.2 Potato dextrose broth for fungal medium. $2.4 \mathrm{~g}$ of potato dextrose broth was mixed with $100 \mathrm{ml}$ of distilled water and was undergone sterilization. This solution was further divided equally in 5 test tubes.

\subsection{Preparation of cultures \\ 2.4.1 Bacterial culture}

A little of pre-made 5 kinds of bacteria were transferred into their respective test tubes using swabs, as an inoculum into equal amounts of distilled water. And kept in an incubator for 24 hours.

\subsubsection{Fungal culture}

A little of pre-made bacteria of 5 types were transferred to individual test tubes using a swab. And it was left in incubator for 48 hours.

\subsection{Preparation of agar medium}

2.5.1 Agar medium for bacterial culture

$0.75 \mathrm{~g}$ of peptone, $0.45 \mathrm{~g}$ of beef extract, $2.25 \mathrm{~g}$ agar and $0.75 \mathrm{~g}$ of $\mathrm{NaCl}$ were mixed with $150 \mathrm{ml}$ of distilled water and was undergone distillation for 45 minutes.

\subsubsection{Agar medium for fungal culture}

$3.6 \mathrm{~g}$ of dextrose nutrient broth and $2.25 \mathrm{~g}$ agar were mixed in $150 \mathrm{ml}$ of distilled water and was undergone sterilization for 45 minutes.

\subsection{Agar well diffusion technique 2.6.1 Agar well diffusion technique by bacterial medium}

The nutrient agar medium prepared was poured equally into 4petriplates and was left to solidify and after solidification using a swab in LAF, 5 kinds of bacteria were transferred individually. And after that using a borer, 5 wells were bored. And in one well antibiotic(A) was poured completely, in other one the extract of Lilum leaves $(\mathrm{L}-\mathrm{ve})$ in another the extract of Ocimum leaves $(T-v e)$, in other one antibiotic along with the nano-particles of Lilum(LT) and finally in the remaining one the Ocimum nano-particles along with antibiotic(TT) is poured using a pipette. And they were left it for 24 hours in an incubator. The zones of inhibition were measured.

\subsubsection{Agar well diffusion technique with fungi medium}

Potato dextrose agar medium was poured equally into 5 sterilized petri plates followed by solidification. And after solidification the 5 fungal cultures were transferred into 5 petriplates individually and then 5 wells are bored in each. One well was filled with antibiotic $(A$, another with the leaf extract of Lilium \{-ve $L)$, other with the extract of Ocimum(-ve T), one with nanoparticles of Lilium and antibiotic in equal amounts(LT) and 
the final one with antibiotic and Ocimum nanoparticles(TT). And those 5 were left in incubator for 48 hours. Then the zone of inhibition was measured.

\section{RESULT AND DISCUSSION}

\subsection{Extraction of plant leaves}

Extraction of Lilium and Ocimum was done by heating the dried and powdered leaves with distilled water for 45 minutes at 60 to $80^{\circ}$ degree Celsius. And after 45 minutes a light Green colored liquid was formed from the solution containing Lilum and a dark Brown color was observed in Ocimum extraction (refer fig; 7.1)

\subsection{Synthesis of nano-particles}

Along with the extractions, $50 \mathrm{ml} 0.1 \mathrm{M}$ Zinc Sulphate and $50 \mathrm{ml} 0.4 \mathrm{M}$ Sodium Hydroxide were added into each of the solutions. And these solutions were put in a shaker for 24 hours. And after 24 hours pellets were formed. And they were centrifuged later for 5 minutes at $5000 \mathrm{rpm}$ and was able to get more pellets formed. And these pellets were separated and dried in a hot air oven for 24 hours. And finally nano-particles were formed (refer fig; 7.2).
In order to find out the inhibition of nanoparticles on anti-bacterial and anti-fungal activity, agar well diffusion method was used. And at the end it was seen that Lilum more than Ocimum, was able to inhibit the growth of bacteria like E.coli, Listeria, P.aeruginosa and S. typhi (refer figs; 7.3.1 to 7.3.4). And in the case of fungal growth inhibition, Ocimum was seen to be much more effective against the fungi- $A$. flavus, $A$. fumigates, A.niger, P.chrysogenum and R.oryzae (refer figs; 7.4.1 to 7.4 .5$)$.

\section{CONCLUSION}

Nano-particles could be made from plant leaf extracts and also it could be used to prevent the microbial growth. For bacterial inhibition, Lilium nano-particles seemed to be much more effective. And for fungal growth inhibition, Ocimum was seemed to be effective.

\section{ACKNOWLEDGEMENT}

We thank CEPCI Kollam and staffs for gave us an opportunity to work on.

3.3 Agar well diffusion method

6.1 Tables

\begin{tabular}{|c|c|c|c|c|c|}
\hline NAME & $\mathbf{A}(\mathbf{c m})$ & $\mathbf{L T}(\mathbf{c m})$ & $\mathbf{T T}(\mathbf{c m})$ & $\mathbf{L - v e}(\mathbf{c m})$ & $\mathbf{T}-\mathbf{v e}(\mathbf{c m})$ \\
\hline Escherichia coli & 2 & 2.5 & 1 & 1.2 & - \\
\hline Listeria monocytogenous & 3 & 0.7 & 1.3 & 0.7 & - \\
\hline Pseudomonas aeruginosa & 2.3 & 0.7 & 0.6 & 0.9 & - \\
\hline Salmonella typhi & 2 & 1 & 1.3 & 0.2 & 0.7 \\
\hline
\end{tabular}

6.1.1: Table containing the diameter of zones of inhibition of bacteria

6.1.2: Table

\begin{tabular}{|c|c|c|c|c|c|}
\hline NAME & $\mathbf{A}(\mathbf{c m})$ & $\mathbf{L T}(\mathbf{c m})$ & $\mathbf{T T}(\mathbf{c m})$ & $\mathbf{L - v e}(\mathbf{c m})$ & $\mathbf{T}-\mathbf{v e}(\mathbf{c m})$ \\
\hline Aspergillus flavus & $0.7 \mathrm{~cm}$ & $0.7 \mathrm{~cm}$ & $1.4 \mathrm{~cm}$ & 0.6 & 0.7 \\
\hline Aspergillus fumigates & 0.6 & 1.1 & 1.4 & 0.6 & - \\
\hline Aspergillus niger & 0.6 & 1.4 & 1.1 & 0.5 & 0.6 \\
\hline Penicillium chrysogenum & 0.7 & 1.5 & 1 & 0.5 & 0.6 \\
\hline Rhizopus oryzae & 1.5 & 1 & 0.8 & 0.7 & 0.6 \\
\hline
\end{tabular}

the diameter of zones of inhibition of fungi 


\subsection{Figures}

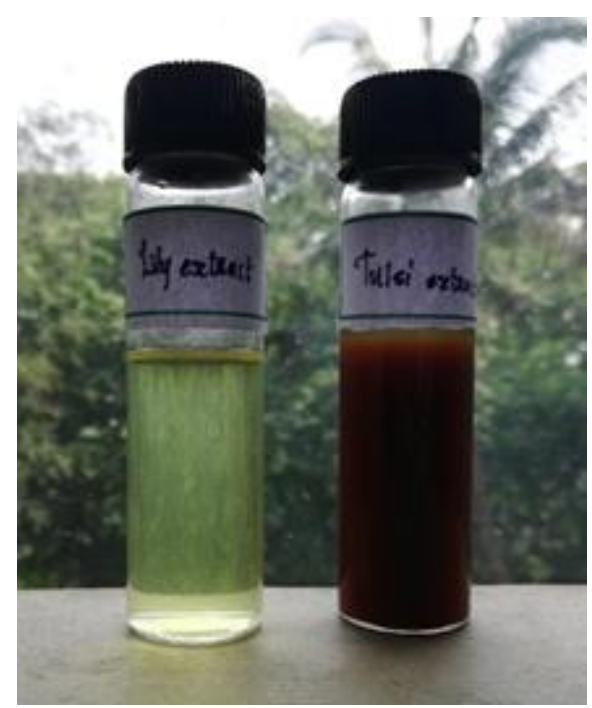

7.1: Extract of leaves

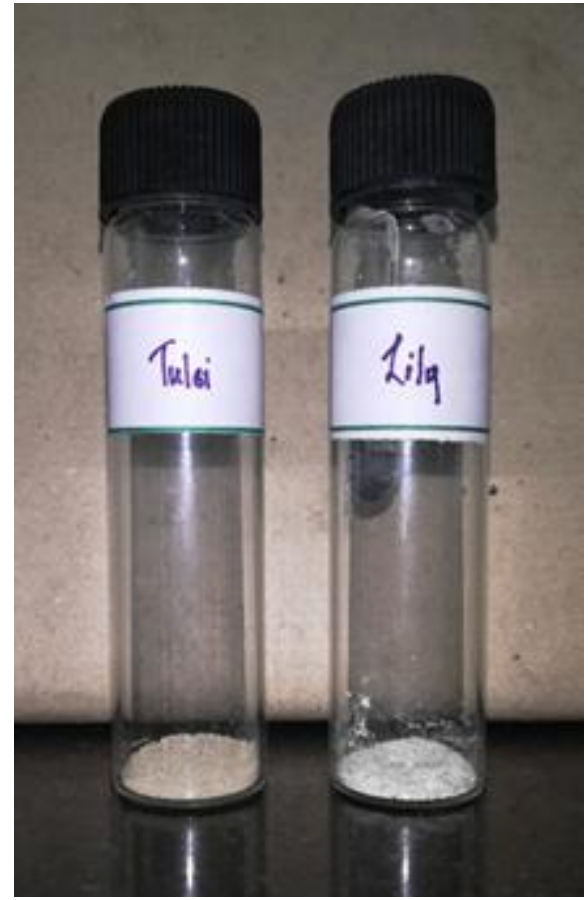

7.2 : Nanoparticles synthesised 
7.3: Agar well diffusion of bacteria

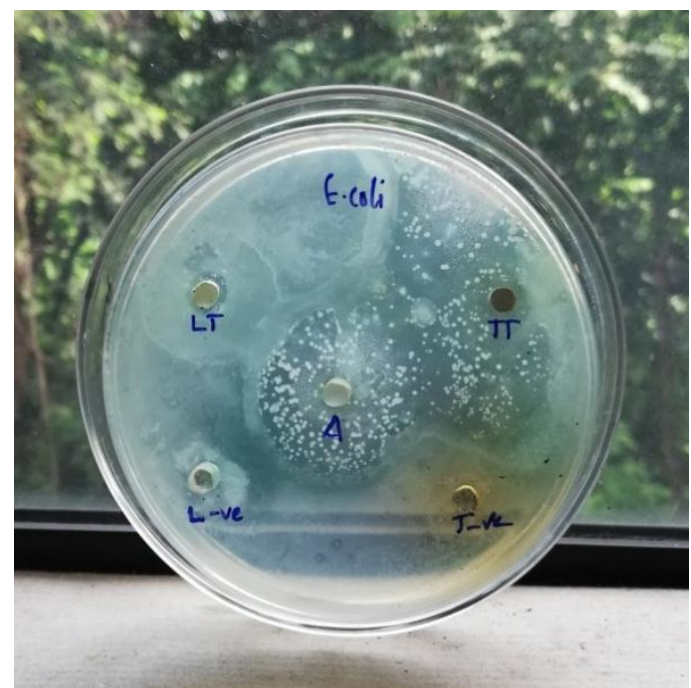

7.3.1: Escherichia coli

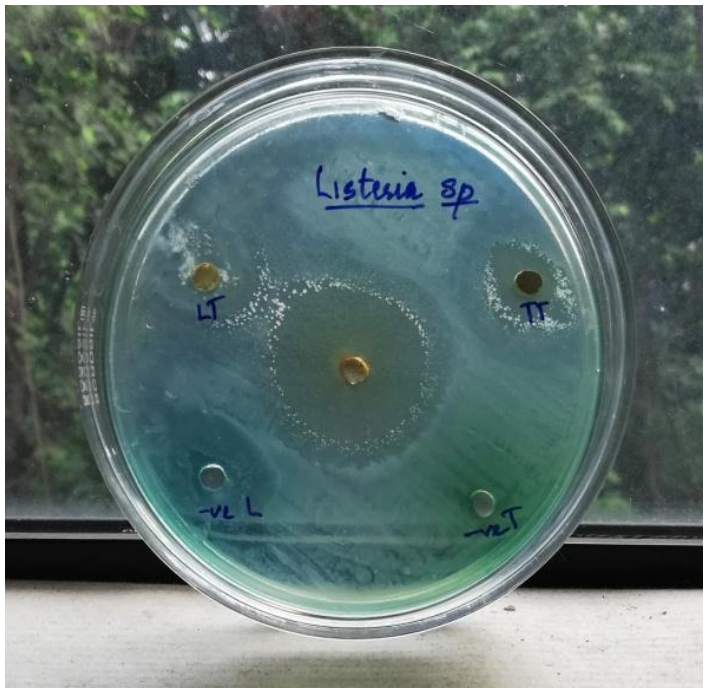

7.3.2: Listeria monocytogenous

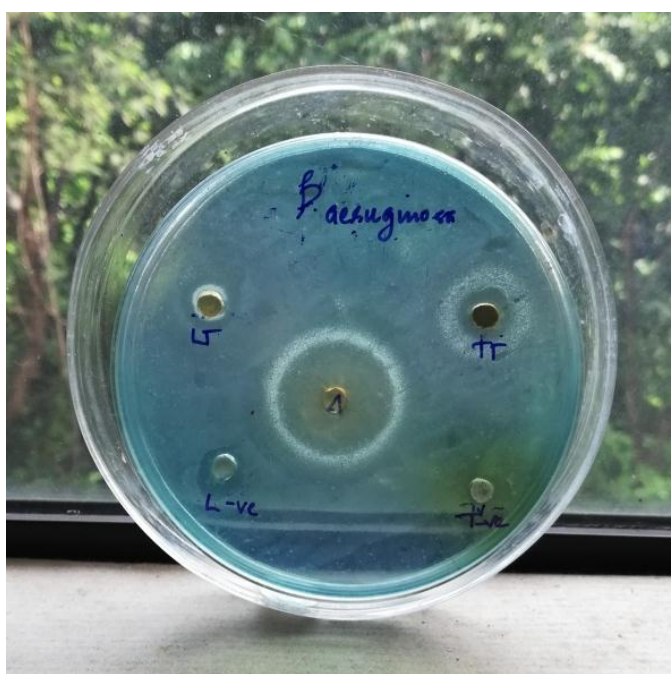

7.3.3: Pseudomonas aeruginosa 


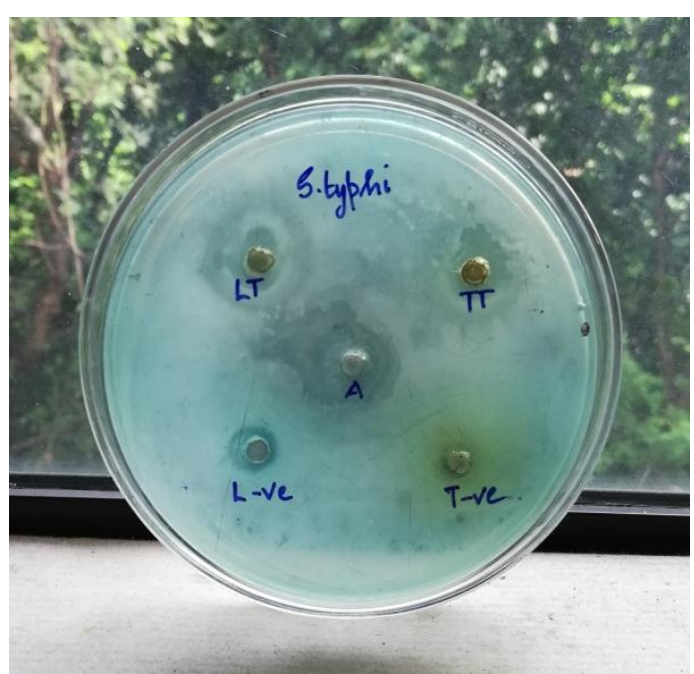

7.3.4: Salmonella typhi

7.4 Agar well diffusion of fungi

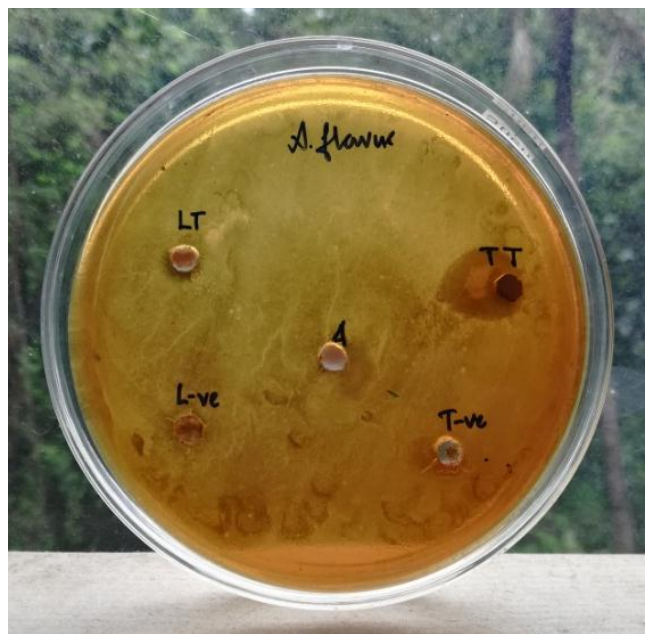

7.4.1: Aspergillus flavus

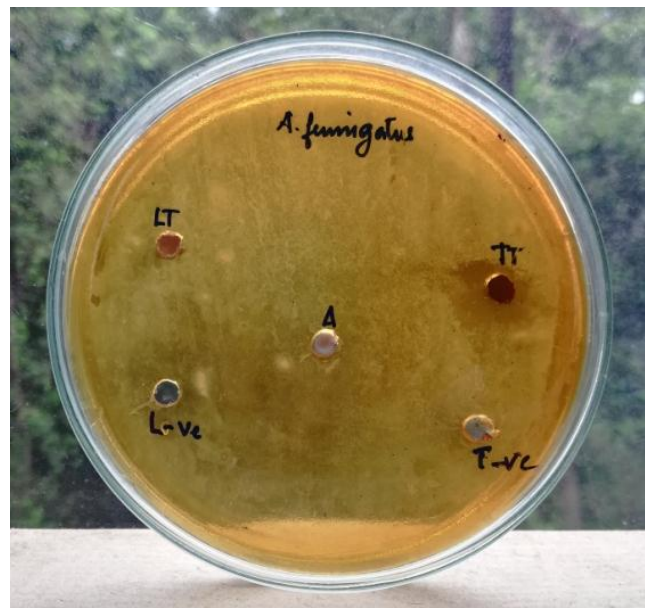

7.4.2: Aspergillus fumigates 


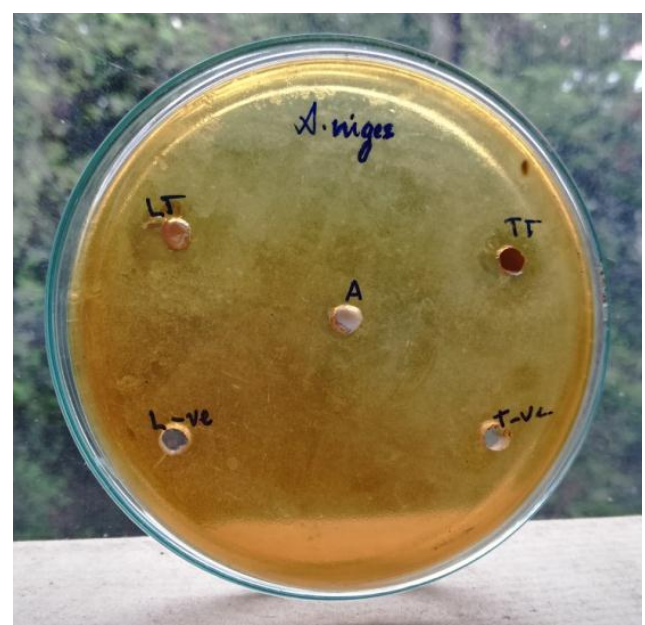

7.4.3: Aspergillus niger

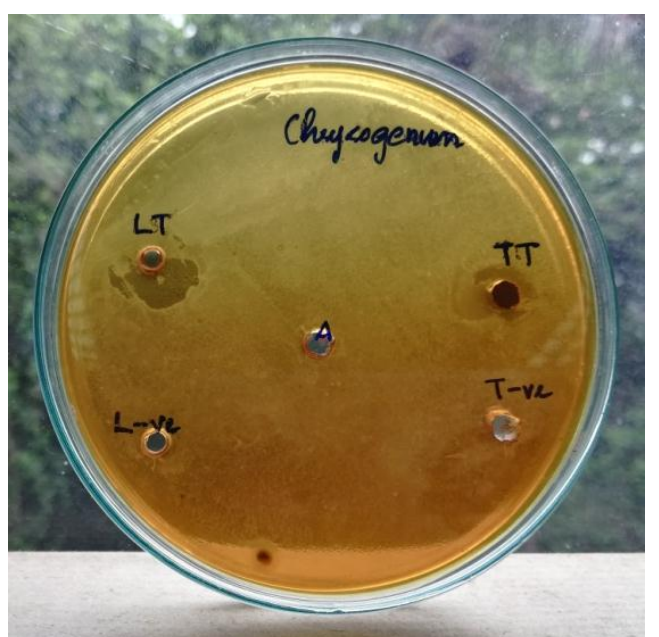

7.4.4: Penicilliumchrysogenum

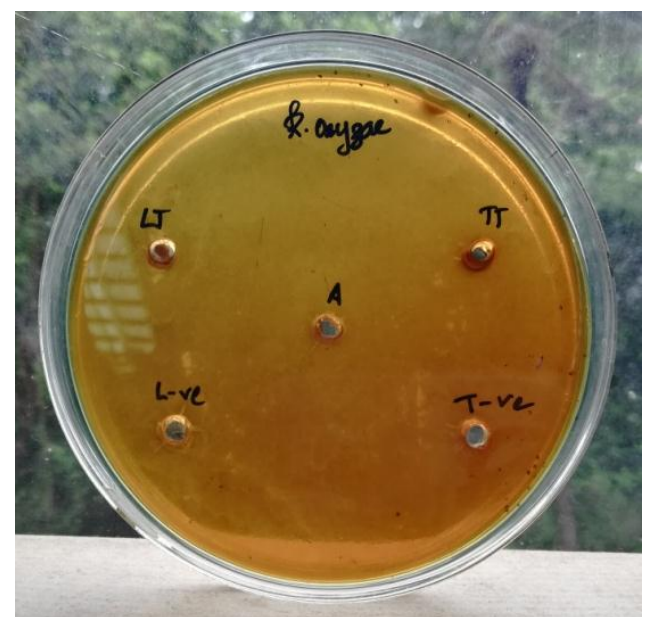

7.4.5: Rhizopusoryzae 


\section{REFERENCES}

1. Batista, Carlos A Silvera, Larson, Ronald G, Kotov and Nicholas A. Nonadditivity of nanoparticle interactions. Science. 2015;350 (6257): 1242477.

doi:10.1126/science.1242477. ISSN 003 6-8075. PMID 26450215.

2. Ibrahim Khan, Khalid Saeed and Idrees Khan. Nanoparticles: Properties, applications and toxicities. Arabian Journal of Chemistry. 2017.https://www.sciencedirect.com/sci ence/article/pii/S1878535217300990.

3. Hewakuruppu YL, Dombrovsky LA, Chen C, Timchenko V, Jiang X, Baek S and Taylor RA. Plasmonic pump-probe method to study semi-transparent nanofluids. Applied

Optics. 2013;52 (24):60416050. Bibcod e:2013ApOpt..52.6041H. doi:10.1364/A O.52.006041. PMID 24085009.

4. Bruchez M, Moronne M, Gin P, Weiss S and Alivisatos AP. Semiconductor nanocrystals as fluorescent biological labels. Science. 1998; 281(5385):20136.

5. Wang S, Mamedova N, Kotov NA, Chen W and Studer J. Antigen/antibody immunocomplex from CdTe nanoparticle bioconjugates. Nano Letters. 2002;2:817-822. doi: $10.1021 / \mathrm{nl0255193.}$

6. Mah C, Zolotukhin I, Fraites TJ, Dobson $\mathrm{J}$, Batich $\mathrm{C}$ and Byrne BJ. Microspheremediated delivery of recombinant AAV vectors in vitro and in vivo. Mol Therapy. 2000;1:S239. doi: $10.1006 /$ mthe.2000.0174

7. Pantarotto D, Partidos CD, Hoebeke J, Brown F, Kramer E, Briand JP, Muller S, Prato M and Bianco A. Chem Biol. 2003 Oct; 10(10):961-6.

8. Edelstein $\mathrm{RL}$, Tamanaha $\mathrm{CR}$, Sheehan PE, Miller MM, Baselt DR, Whitman LJ and Colton RJ. Biosens Bioelectron. 2000;14(10-11):805-13.

9. Nam JM, Thaxton CS and Mirkin CA. Science. 2003; 301(5641):1884-6.

10. Mahtab R, Rogers JP and Murphy CJ. Protein-sized quantum dot luminutesescence can distinguish between "straight", "bent", and "kinked" oligonucleotides. J Am Chem Soc. 1995;117:9099-9100.
11. Ma J, Wong H, Kong LB and Peng KW. Biomimetic processing of nanocrystallite bioactive apatite coating on titanium. Nanotechnology. 2003;14:619 -623. doi: 10.1088/0957-4484/14/6/310.

12. Altervista Flora Italiana and Gigliobianco di S. Antonio, Madonna lily, Liliumcandidum L.

13. Warrier PK. Indian Medicinal Plants. Orient Longman. 1995;168. ISBN 9780-86311-551-6.

14. Staples, George and Michael S Kristiansen. Ethnic Culinary Herbs. University of Hawaii Press. 1999;73. ISBN 978-0-8248-2094-7.

15. Sundaram $R$ Shanmuga, Ramanathan M, Rajesh R, Satheesh B and Saravanan D. Lc-Ms Quantification of Rosmarinic Acid and Ursolic Acid in TheOcimumSanctumlinn. Leaf Extract (Holy Basil, Tulsi). Journal of Liquid Chromatography \& Related Technologies. 2012;35(5):634. doi:10.1 080/10826076.2011.606583.

16. Upadhyay Atul K, Chacko Anita R, Gandhimathi A, Ghosh Pritha, Harini K, Joseph, Agnel P, Joshi, Adwait G, Karpe, Snehal D, Kaushik, Swati, Kuravadi, Nagesh, Lingu, Chandana S, Mahita J, Malarini, Ramya, Malhotra Sony, Malini, Manoharan, Mathew, Oommen K, Mutt, Eshita, Naika, Mahantesha, Nitish, Sathyanarayanan, Pasha, Shaik Naseer, Raghavender, Upadhyayula S, Rajamani, Anantharamanan, Shilpa S, Shingate Prashant N, Singh, Heikham Russiachand, Sukhwal, Anshul, Sunitha, Margaret S, Sumathi, Manojkumar, Ramaswamy S, Gowda, Malali, Sowdhaminutesi and Ramanathan. Genome sequencing of herb Tulsi (Ocimumtenuiflorum) unravels key genes behind its strong medicinal properties. BMC Plant Biology. 2015;15 (1):

212. doi:10.1186/s12870-015-0562x. PMC 4552454. PMID 26315624.

17. Chadburn H. Liliumcandidum. The IUCN Red List of Threatened Species. 2014. e.T203356A2764337. Downloaded on 12 May 2019. 